\title{
Trabalho doméstico: análise da perceção do trabalhador após a regulamentação da lei complementar $n^{0} 150 / 2015$
}

Domestic work: analysis of the worker's perception after the supplementary law no. 150 of 2015

Leila Vaz da Silva ${ }^{1}$; Daniela Assis Alves Ferreira ${ }^{2}$.

${ }^{1}$ E-mail:

leila.silva@izabelahendrix.metodista.br Centro Universitário Metodista Izabela Hendrix (CEUNIH)

2 E-mail:

daniela.ferreira@izabelah

endrix.metodista.br

Centro Universitário

Metodista Izabela Hendrix

(CEUNIH)
Resumo: $O$ presente trabalho tem como finalidade analisar o conhecimento do trabalhador doméstico a respeito dos seus direitos e as mudanças percebidas pelos mesmos, assim como levantar os perfis demográficos dos profissionais pesquisados. A pesquisa será direta e objetiva e levantará dados primários por meio da aplicação de formulários e após será feita uma análise quanti-qualitativa. O referencial teórico abordou assuntos relacionados à definição e características do empregado doméstico, história do trabalho doméstico no Brasil e o reconhecimento profissional, social e jurídico proveniente com a Emenda Constitucional $\mathrm{N}^{\circ} 72 / 2013$. A metodologia usada quanto a pesquisa foi a descritiva e a técnica utilizada foi o levantamento de dados primários em campo a partir da adoção de 100 formulários semiestruturados aplicados em Belo Horizonte.

Palavras-chave: Empregado; Doméstico; Pesquisa; Lei; Mudanças; Quanti-qualitativa.

Abstract: The present study aims to analyze the knowledge of the domestic worker regarding their rights and the changes perceived by them, as well as to raise the demographic profiles of the professionals surveyed. The research will be direct and objective and will raise primary data through the application of forms and after will be made a quanti-qualitative analysis. The theoretical framework addressed issues related to the definition and characteristics of domestic servants, the history of domestic work in Brazil and the professional, social and legal recognition provided by Constitutional Amendment No. 72/2013. The methodology used in the research was descriptive and the technique used was the collection of primary data in the field from the adoption of 100 semistructured forms applied in Belo Horizonte.

Keywords: Employee; Domestic; Research; Law; Changes; Quantiqualitative. 


\section{pontěditora}

\section{Introdução}

Pretendeu-se, com este trabalho, realizar um estudo da situação profissional dos empregados domésticos a partir de uma visão social e legal. Esta última, destaca-se pelo fato de que esses trabalhadores obtiveram a conquista dos seus direitos trabalhistas básicos apenas a partir de 2013, quando o Brasil passa a adotar uma legislação trabalhista específica para esse tipo de atividade. Será apresentada uma breve evolução histórica desse segmento, que por muito tempo foi esquecido perante a lei e que, hoje, é tão discutido no meio jurídico e social.

Anteriormente, apesar do decreto de número 5.452, criado em 1943 - onde fora instituída a Consolidação das Leis do Trabalho (CLT), que uniformizou o direito do trabalho no Brasil, tornando-o um direito autônomo - o trabalhador doméstico não foi abrangido por esta Lei (DAMASCENO; CHAGAS, 2013). O trabalho doméstico somente foi regulamentado em 1972, pela Lei $\mathrm{n}^{\mathrm{o}} 5.859$, definindo-o em seu artigo $1^{\circ}$, como "aquele que presta serviços contínuos sem fins lucrativos à pessoa ou família no âmbito residencial".

Dessa forma, o fator que diferenciava o emprego doméstico dos demais era seu caráter não-econômico, uma vez que a atividade seria exercida no âmbito residencial do empregador. Podem ser consideradas da categoria do empregado doméstico o profissional cozinheiro, babá, governanta, lavadeira, faxineira, motorista particular, acompanhante de idosos, entre outras ocupações (BRASIL, 2013).

Após a promulgação da Emenda Constitucional $n^{0}$ 72, em abril de 2013, uma nova regulamentação para os direitos dos empregados domésticos foi editada pela Lei Complementar $n^{\circ} 150$ de 2015. Além de regulamentar a atividade, ela criou ainda o Simples Doméstico, com a finalidade de facilitar o cumprimento das obrigações dos empregados domésticos em relação ao Fisco, os cálculos dos valores legais devidos decorrentes da relação trabalhista, a prestação de informações, geração da guia de recolhimento do FGTS e para os pagamentos incidentes sobre a relação de emprego doméstico no País (BRASIL, 2015).

Segundo dados do Instituto Brasileiro de Geografia e Estatística (IBGE), em 2016, existiam no Brasil 6.152 milhões de trabalhadores domésticos, dos quais $92 \%$ eram mulheres. Em relação à seguridade social, apenas $42 \%$ dos trabalhadores contribuíam 


\section{pontěditora}

para a previdência social e somente $32 \%$ possuíam carteira de trabalho assinada. Em sua maioria, esses trabalhadores possuem uma remuneração mensal, mas são as diaristas as que enfrentam as condições mais precárias de trabalho (OIT BRASILIA, 2017).

No Brasil, no terceiro trimestre de 2017 ocorreu um aumento de 2,9\% de trabalhadores domésticos, quando comparado ao trimestre anterior. Esse número corresponde a aproximadamente 177 mil novos postos de trabalho, o que contribuiu para a queda da taxa de desocupação nacional, passando de $12,8 \%$ para $12,2 \%$, quando comparado ao mesmo trimestre de 2016. Entretanto, a maioria desses trabalhadores são empregados sem carteira, que buscam trabalho por falta de espaço na economia formal (AGÊNCIA DE NOTÍCIAS IBGE, 2017).

De acordo com dados da Organização Internacional do Trabalho (OIT), de uma pesquisa realizada em 117 países, em 2010 o mundo possuía cerca de 52 milhões de empregados domésticos, sendo que quase 30\% (15,7 milhões) do total desses trabalhadores estavam completamente excluídos de qualquer tipo de cobertura por legislação laboral. E apenas 5,2 milhões (10\%) dos empregados domésticos tinham acesso a proteção jurídica igual a dos demais trabalhadores. Caso fossem contabilizados os menores de 15 anos, que somam aproximadamente 7,4 milhões, seriam mais de 23 milhões de pessoas sem proteção trabalhista. Ainda segundo o estudo, dos 52 milhões de empregados domésticos no mundo, $83 \%$ são mulheres. A organização Internacional do trabalho ainda afirma que foi registrado aumento de mais de 19 milhões de trabalhadores domésticos em todo o mundo, entre os anos de 1990 e 2010 (OIT, 2013).

Essa atividade profissional é considerada como essencialmente leiga, podendo ser desempenhada por pessoas sem nenhuma formação escolar. As condições adversas enfrentadas por esses trabalhadores se relacionam a fatores estruturais, sociais, simbólicos e conjunturais inter-relacionados ao desempenho destas atividades (MUNHOZ, et al., 2017). Ao analisar o trabalho doméstico no Brasil fica evidente a sua precariedade, desvalorização social e a gênese da invisibilidade com a qual é caracterizada (SILVA, 2017). 
A partir do que foi discutido até aqui, pode-se destacar a afirmação de Cunha e Gomes (2007, p. 11), sobre o assunto:
A sujeição, a subordinação e a desumanização, que davam inteligibilidade à experiência do cativeiro, foram requalificadas num contexto posterior ao término formal da escravidão, no qual relações de trabalho, de hierarquias e de poder abrigaram identidades sociais se não idênticas, similares àquelas que determinada historiografia qualificou como exclusivas ou características das relações senhor - escravo.

A aquisição de novos direitos dos trabalhadores, garantidos por normas constitucionais e legislação específica, com o propósito de propiciar maior segurança jurídica aos profissionais domésticos, tem assustado o empregador por conta do que consideram "burocracia" e, vem limitando o número de vagas ofertadas no mercado de trabalho, prejudicando esse profissional (BARBOSA, 2015).

Associado a esse fato, destaca-se que muitos profissionais ainda não conhecem os direitos que lhe foram recentemente garantidos por lei. Diante desse contexto, torna-se relevante um estudo que vise a avaliar como é a percepção dos empregados domésticos diante dessas mudanças.

Desta forma, o objetivo deste estudo é analisar as diferenças percebidas pelos profissionais domésticos em relação às oportunidades e condições de trabalho, após a mudança da lei que ampliou os benefícios trabalhistas a esse segmento profissional.

A realização deste trabalho é de grande importância, uma vez que, os novos direitos dos empregados domésticos, e suas consequências para a relação patrão-empregado, têm sido alvo de constantes discussões. Entretanto, podem ser observadas, com frequência, dúvidas relacionadas aos direitos vigentes (FARACO, 2014).

O objetivo deste trabalho torna-se importante, pois a vivência relatada pelo trabalhador doméstico possibilita maior conhecimento sobre o tema, para empregado e empregadores. De forma geral, muitos não possuem conhecimento sobre as obrigações necessárias para a formalidade e legalidade dessa relação. Este conhecimento auxilia nos procedimentos de admissão, demissão, pagamento, garantia de direitos e deveres, orientando a aplicação correta dessas determinações. 
Inicialmente foi realizada uma conceituação do que seja o trabalho doméstico e as características desse segmento profissional. No segundo momento fez-se uma retomada histórica abordando a origem do vínculo empregatício doméstico no Brasil, colocando sob análise as questões sociais e históricas envolvidas nessa relação profissional. Por fim, foram analisadas as condições em que muitas trabalhadoras se encontram relacionadas principalmente à questão salarial, jornada de trabalho, e outros aspectos que envolvem a atividade

\section{2 - Empregado doméstico: breve definição e características}

A palavra "doméstico" tem origem no latim domesticus, que se compreende por casa de família; e de domus, que significa casa, lar. Lar consiste a parte da cozinha onde o fogo é aceso - a lareira - e, em um sentido mais amplo, significa habitação (MARTINS, 2004).

O trabalho representa a atividade básica do homem e da mulher, sendo fundamental para a socialização. A força de trabalho foi explorada de diferentes formas e em diferentes contextos históricos, atendendo a necessidade de cada momento. Várias foram às formas de organização e exploração do trabalho. Na antiguidade, o trabalho significava uma atividade própria daqueles que haviam perdido a liberdade, resultando em uma relação de castigo e sofrimento impostos. Entretanto, a partir da reforma protestante, para a sociedade capitalista, o trabalho constitui algo necessário e digno (SILVA, 2016).

A autora defende que, por um longo período, não existiu uma regulamentação específica para a categoria dos empregados domésticos, sendo aplicados os preceitos do Código Civil. A partir da Lei $\mathrm{n}^{\mathrm{o}} 5.859$ de 1972, passa a ser regulamentada a profissão de empregado doméstico, sendo definida como "aquele que presta serviços de natureza contínua e de finalidade não lucrativa a pessoa ou a família, no âmbito residencial”. Assim, Araújo (2015) esclarece que o empregado doméstico pode ser definido como a pessoa física que, com intenção de lucro, trabalha para outras pessoas físicas, no âmbito residencial, de forma não eventual, prestando serviços de natureza contínua com pessoalidade, onerosidade e subordinação. 
Segundo Martins (2013), as expressões "trabalhador em domicílio" e "empregado doméstico" não possuem o mesmo significado e definem que trabalhador em domicílio seria aquele que, a partir do seu trabalho, mantém com o empregador domiciliar uma relação com finalidade lucrativa. Já o empregado doméstico mantém, em favor do outro, uma relação de trabalho, subordinação e dependência da outra pessoa sem a finalidade de lucro. Ou seja, seria uma relação onde não existe a premissa de auferir lucro pelo patrão.

Desta forma, o serviço doméstico remunerado, representa aquele prestado por meio de uma relação jurídica de trabalho, na qual o trabalhador busca uma contrapartida financeira pela execução desse serviço. De modo geral, podem ser citadas como características do trabalho doméstico remunerado: trabalho vinculado à esfera residencial; ligado à história de escravidão, colonialismo e outras formas de servidão; composto em sua maioria por mulheres em situação de vulnerabilidade social; e que não possibilita ascensão profissional (BARROS, 2013).

Um estudo realizado por Marteleto (2011), afirma que o trabalho doméstico consiste em um grande número de tarefas distintas entre si, remuneradas, repetitivas e exaustivas, efetuadas por uma pessoa no âmbito residencial, desde que não seja em sua própria unidade domiciliar, compreendendo atividades ligadas à cozinha, limpeza do domicílio e cuidados com a família, de atenção aos idosos, crianças e pessoas com deficiência, animais, dentre outras.

\section{1 - História do trabalho doméstico no Brasil}

O surgimento do trabalhador doméstico no Brasil se deu a partir da chegada dos escravos africanos, trazidos para a "casa grande" a fim de desempenhar atividades do lar, como arrumar, cozinhar e lavar para os senhores e suas famílias. Também desempenhavam funções como amas de leite, aias, transmissor de recados, jardineiros, pajens e costureiras. Em sua maioria, este tipo de trabalho era realizado por homens ou mulheres negras e até mesmo crianças, que eram escolhidos pelos senhores pelo critério da aparência, limpeza e força (DAMASCENO; CHAGAS, 2013).

Vale ressaltar que, no período do Brasil Colônia, o foco do trabalho doméstico 


\section{pontěditora}

fundamentava-se, principalmente em mulheres negras, prevalecendo um código moral no qual patrões e patroas deveriam prover a proteção, moradia, vestuário e alimentação aos seus criados e criadas, em troca de fidelidade e obediência. Desta forma, pode-se perceber que, na atualidade, a atividade doméstica ainda apresenta resquícios da escravidão (SILVA, 2017).

Silva (2017) destaca que, no Brasil Império, mesmo após a libertação dos escravos a partir da Lei Áurea, muitos se mantiveram à disposição de seus empregadores, pois não possuíam o que fazer ou para onde ir.

Já, no período do Brasil República, a empregada doméstica começou a deixar a invisibilidade, a partir da criação do Primeiro Sindicato das Empregadas Domésticas do Brasil, em Santos (SP), por Laudelina de Campos Melo; e dos direitos previstos na Consolidação das Leis Trabalhistas e promulgação da Constituição de 1988 (SILVA, 2017).

A profissão de empregado doméstico era vista com maus olhos pela sociedade, sem a existência de regulamentação para ordenamento jurídico que tratasse apenas desta categoria. Todas as relações envolvendo estes empregados eram abrangidas pelo Código Civil de 1916, que buscava a uniformização dos procedimentos e a concentração de dispositivos normativos. Somente a partir da Consolidação das Leis Trabalhistas (CLT) que todas as locações de serviços foram abrangidas pelo Código Civil. Em 1923, foi aprovado por meio do Decreto $\mathrm{n}^{\mathrm{o}} 16.107$ o regulamento de locação de serviços domésticos, como o realizado pelas cozinheiras, ajudantes e arrumadeiras (DAMASCENO; CHAGAS, 2013).

Em 1972 com o surgimento da Lei 5.859 os trabalhadores domésticos começam a conquistar seus direitos, sendo ampliado ainda mais em 1988, com a Constituição Federal do Brasil (DAMASCENO; CHAGAS, 2013).

A criação da CLT estabeleceu normas coletivas e individuais de trabalho que em tese, buscava sanar a precariedade das normas de proteção ao trabalho no Brasil, entretanto, afastou o trabalho doméstico do seu campo de proteção. Ao excluir os empregados 


\section{pontěditora}

domésticos dos direitos trabalhistas, a CLT se configurou como o primeiro dispositivo legal a desvalorizar de maneira expressa o trabalho doméstico em relação as demais categorias de trabalho (SILVA, 2016a).

Tais fatos tornam fácil a verificação que o trabalho doméstico no Brasil sempre buscou atender os anseios de uma sociedade que desprestigiava o trabalho prestado no ambiente domiciliar, constituindo uma questão de cunho social e histórico. Essa distinção constitui fruto, entre diversos outros fatores da ação segregadora do Legislativo e de uma sociedade pouco solidária e conivente. Todos esses fatos, associados a um Judiciário conservador, tornam ainda mais crítico debate do tema (MACIEL, 2016).

Apesar desse quadro social, era notória e crescente a necessidade de reconhecimento de outros direitos trabalhistas aos empregados domésticos, tendo em vista que inexistiam motivos para o tratamento desigual desses profissionais, já que prestam serviços de relevância social e, portanto, devem ser amparados pelo Direito do Trabalho com equidade em relação às demais categorias profissionais (MACIEL, 2016).

Araújo (2015) relata que durante o regime militar, a Lei 5.859/72, define em seu artigo $1^{\mathrm{o}} \mathrm{o}$ trabalhador doméstico, assegurando a essa categoria profissional o direito ao registro do contrato de trabalho em carteira, benefícios previdenciários e vinte dias de férias. Apesar dos benefícios adquiridos, essa lei não equiparou aos trabalhadores que possuíam contratos de trabalho regidos pela CLT.

Paulatinamente alguns direitos foram reconhecidos em leis, mesmo que de modo espaçado, como por exemplo, a Lei $n^{\circ} 7195 / 1984$ que acarretou na responsabilização civil das agências de empregados domésticos; a Lei $n^{\circ}$ 8009/1990 que resultou na possibilidade de penhorabilidade do bem de família quando da execução trabalhista do empregado doméstico; a Lei ${ }^{0}$ 10208/2001 que garantiu a inscrição do trabalhador no FGTS e seguro desemprego e, por fim, a Lei $n^{\circ} 11324 / 2006$ garantiu a estabilidade provisória a gestante e vedação de desconto em razão da alimentação, moradia, vestuário e higiene (MIKOS, 2015).

Uma importante modificação da Lei n ${ }^{\circ} 5.859 / 72$ ocorreu em 2006, a partir da aprovação 


\section{pontěditora}

da Lei $\mathrm{n}^{\mathrm{0}} 11.324$ que acrescentou direitos trabalhistas para a categoria doméstica ocasionando em aperfeiçoamento jurídico desses empregados que passou a ter direitos como: proibição de descontos por fornecimento de vestuário, alimentação, higiene, moradia e vestuário, direito de férias anuais de 30 dias, como pelo menos, 1/3 a mais que o salário normal e $13^{\circ}$ salário (ARAÚJO, 2015).

Também vale destacar a OIT, tratada na Convenção do Trabalho Decente para Trabalhadoras e Trabalhadores Domésticos que em 2011 discutiu a situação da empregada doméstica, culminando com a criação da PEC das Domésticas no Brasil.

Em 2013 a proposta de emenda constitucional, denominada PEC das domésticas, incluiu novos direitos aos empregados domésticos, trazendo uma nova realidade para uma classe discriminada e desprotegida (DAMASCENO; CHAGAS, 2013).

Por fim, a promulgação da Lei $\mathrm{n}^{\circ}$ 150/2015, conhecida como a Nova Lei do Trabalho Doméstico (NLTD) que revogou a Lei $\mathrm{n}^{\mathrm{o}} 5859 / 72$ trouxe em seu artigo $1^{\circ}$ uma definição jurídica do empregado doméstico como "aquele que presta serviços de forma contínua, subordinada, onerosa e pessoal e de finalidade não lucrativa à pessoa ou a família, no âmbito residencial destas, por mais de dois dias por semana" (MACIEL, 2016).

Portanto, torna-se possível concluir que até meados da década de 1970, esses trabalhadores sequer eram reconhecidos pela prestação de seus serviços, e a Consolidação das Leis Trabalhistas (CLT) de 1943 ignorou todos esses profissionais; sendo que, somente em 2013 a profissão foi abrangida por leis essenciais as quais os demais trabalhadores de outras áreas já eram assegurados.

\section{2 - Reconhecimento profissional, social e jurídico proveniente com Lei} Complementar $n^{0} 150$ de 2015

Apesar da grande importância da CLT, torna-se oportuno destacar que, apesar desta ser a primeira legislação que tratou dos aspectos gerais da relação de trabalho, evitando o desamparo do trabalhador em seu artigo $7^{\circ}$, os preceitos que foram contemplados na consolidação não foram aplicados aos empregados domésticos, não sendo tutelados por 


\section{pontěditora}

este dispositivo legal. Essa exclusão dos trabalhadores domésticos da CLT apresenta-se como um reflexo do contexto social, econômico e histórico do país, permanecendo por considerável período, permitindo que o empregado doméstico continuasse desprotegido, do ponto de vista legal, por quase 30 anos (ARAÚJO, 2015).

Em 2013, a Constituição Federal de 1988 foi alterada garantindo aos empregados alguns direitos que ainda não usufruíam, como por exemplo, relação de emprego protegida contra despedida arbitrária ou sem justa causa, remuneração do trabalho noturno superior ao diurno, seguro desemprego, Fundo de Garantia por Tempo de Serviço, fixação de jornada de trabalho, remuneração do trabalho extraordinário, salário família, redução dos riscos inerentes ao trabalho, reconhecimento das convenções e acordos coletivos, assistência gratuita a filhos e dependentes, seguro contra acidentes de trabalho, isonomia salarial; proibição do trabalho noturno, perigoso ou insalubre ao menor de 18 anos. Ressalta-se que alguns desses direitos passaram a ter validade imediata após a publicação da emenda Constitucional no 72/2013 (BRASIL, 2015).

A Emenda Constitucional n $n^{\circ}$. 72/2013, foi promulgada em 02 de abril do de 2013. Esta PEC - Proposta de Emenda Constitucional nasceu como resposta do Brasil à recomendação $n^{\circ} 201$ da Organização internacional do trabalho que tinha por objetivo garantir aos trabalhadores domésticos, como aos demais trabalhadores, condições justas e dignas de emprego (SILVA, 2017).

Com a promulgação da EC 72/2013, a qual representa importante marco civilizatório na sociedade brasileira, a categoria profissional dos trabalhadores domésticos passou a ter assegurados novos direitos, o que, sem dúvida alguma, demonstra avanços sociais no que diz respeito à valorização do trabalho e à dignidade da pessoa humana, esta última, consagrada pela Constituição de 1988 como fundamento da República Federativa do Brasil (MARTINS, 2013).

A Emenda, no plano jurídico normativo, estabeleceu a igualdade de direitos trabalhistas entre os trabalhadores domésticos e as demais categorias, ficando pendente as questões relativas ao seguro desemprego, fundo de garantia, proteção contra dispensa sem justa causa, salário família, seguro contra acidentes de trabalho e ainda assistência gratuita 


\section{pontěditora}

aos filhos e dependentes até completarem cinco anos de idade em creches e pré-escola (SILVA, 2016).

A Lei $n^{\circ} 150 / 2015$ regulamentou as matérias que estavam pendentes excluindo as diaristas do âmbito de reconhecimento de vínculo empregatício, sendo necessários dois dias de trabalho contínuo por semana em uma mesma residência, flexibilização da jornada de trabalho, permissão de jornada de trabalho $12 \times 36$, instituição do simples doméstico, possibilidade de receber multa rescisória de 40\% do FGTS e um percentual de contribuição de 3,2\%. Nota-se que as alterações da Lei Complementar 150/2015 beneficiou, sobremaneira, os empregadores domésticos, sendo pouco efetivas para a vulnerabilidade que estão acometidos os trabalhadores domésticos (SILVA, 2016).

A partir disso, conclui-se o importante marco para a categoria, uma vez que assegurou novos direitos, demonstrando avanços sociais referentes à valorização do trabalho e a dignidade.

\section{3 - Metodologia}

Para que uma pesquisa possa ser caracterizada como científica torna-se necessário que a mesma seja desenvolvida por meio de planejamento, sendo organizada e sistemática, aplicando procedimentos científicos. De acordo com Vergara (2007), os tipos de pesquisa podem ser definidos por dois critérios básicos: quanto aos fins e quanto aos meios. Neste trabalho, quanto aos fins, a pesquisa se deu por estudo descritivo e quanto aos meios foram pesquisa de campo e estudo de caso.

Vergara (2007) argumenta que a pesquisa descritiva expõe as características de determinada população ou fenômeno, estabelece correlações entre variáveis e define sua natureza. Gil (2008) destaca que pesquisas descritivas são aquelas que tem por finalidade a descrição das características de determinada população como idade, sexo nível de escolaridade, estado de saúde mental e que focam descobrir a existência de associações entre variáveis.

A técnica utilizada foi o levantamento de dados primários em campo. Segundo Mattar (2008), tem-se a pesquisa de campo realizada em ambiente real, não havendo possibilidade de controle das variáveis medidas. O estudo de caso na opinião de Mattar 


\section{pontěditora}

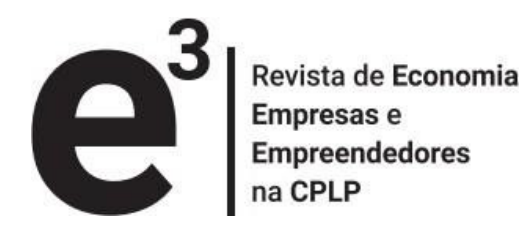

(2008) pode envolver o exame de registros já existentes, a observação da ocorrência do fato, entrevistas estruturadas, entrevistas não estruturas, etc. O objeto do estudo pode ser uma pessoa, um grupo de pessoas, uma organização, um grupo de organizações ou uma situação.

Em relação ao universo e amostra de uma pesquisa, entende-se por universo o "conjunto de elementos (empresas, produtos, pessoas, por exemplo) que possuem as características que serão objeto de estudo" (VERGARA, 2007, p. 50). Seguindo a mesma ideia, Cozby (2006, p.145) afirma que o universo se compõe "por todos os indivíduos de interesse para o pesquisador". Segundo a Pesquisa de emprego e desemprego por meio da sua última pesquisa que foi apresentada no boletim (PED, 2014), estima-se que a quantidade de trabalhadores domésticos na região metropolitana de Belo Horizonte seja de 127 mil pessoas, sendo considerado esse número o universo desse estudo.

De acordo com Mattar (2008) os tipos de amostragem são classificados em dois grupos: não probabilísticas que consiste na seleção dos elementos pelo pesquisador e geram amostras probabilísticas, e se subdivide nas categorias básicas (conveniência ou acidental, intencional ou julgamento e quotas ou proporcional) e variações (tráfego, autogerada e desproporcional e as probabilísticas). Cabe ressaltar que as probabilísticas consistem na amostragem em que cada elemento da população tem uma chance conhecida e diferente de zero de ser selecionado para compor a amostra e são subdivididas em aleatória simples, aleatória especificada e conglomerado (Sistemática ou Área). A amostra por conveniência constitui-se não probabilística e formada por indivíduos de fácil acesso e disponível em determinado local e momento. Os indivíduos vão sendo inseridos na pesquisa até que se atinja a dimensão pretendida (FORTIN, 2003).

Assim, o estudo adotou amostragem não probabilística por conveniência, e, apesar de nessa modalidade, não haver obrigatoriedade de maior rigor estatístico, optou-se, para fins de representatividade da amostra, adotar a tabela de Arkin e Colton (1995), e assim foram aplicados formulários a 100 profissionais da categoria pesquisada. Estabeleceu-se desse modo, margem de erro de 10\% com um intervalo de confiança de $95 \%$. 


\section{pontěditora}

Em relação ao instrumento de coleta de dados, nesse estudo os dados primários acadêmico foram obtidos por meio da adoção de formulários semiestruturados, de fácil entendimento, aplicados pessoalmente, em forma de entrevista anônima, garantindo conforto e segurança ao entrevistado.

O formulário, composto de 23 perguntas envolvem levantamento do perfil demográfico, bem como questões relacionadas aos objetivos específicos do estudo, objetivando identificar se os profissionais pesquisados perceberam mudanças em relação as oportunidades e condições de trabalho após a mudança da lei, além de outras questões que permitam atender o objetivo do estudo.

Após a coleta de dados esse estudo adotou a análise de dados do tipo quali-quantitativa, pois se pretendeu estimular os entrevistados a falarem, pensarem livremente e exporem suas opiniões e pontos de vistas sobre o tema. E, pretendeu-se também levantar dados para serem trabalhados estaticamente os perfis desses profissionais. Figueiredo (2007) afirma que a análise quanti-qualitativa consiste em um método que associa análise estatística à investigação dos significados das relações humanas, privilegiando a melhor compreensão do tema a ser estudado, auxiliando assim, a interpretação dos dados obtidos. Polit, Beck e Hungler (2004) afirmam que a abordagem quanti-qualitativa permite complementação entre palavras e números, as duas linguagens fundamentais da comunicação humana. Desta forma, a escolha desse tipo de pesquisa amparou-se no fato de haver no estudo, a interação entre a análise estatística e a análise do discurso dos participantes do estudo.

\section{4 - Apresentação dos resultados}

A pesquisa se deu por meio de aplicação de formulários voltados para análise do perfil demográfico dos trabalhadores domésticos, sobre seus conhecimentos a respeito dos seus direitos trabalhistas e sua percepção sobre o mercado de trabalho. Os formulários foram aplicados durante os meses de julho e agosto de 2018. A pesquisa contou com 100 participantes, número definido para a amostragem do estudo. Em sua totalidade, a pesquisa foi realizada com mulheres e todas trabalham em regiões de bairros nobres de Belo Horizonte, como bairro Santo Antônio, Funcionários e Sion. 
O gráfico 1 apresenta a idade dos participantes do estudo.

\section{Gráfico 1 - Idade das entrevistadas}

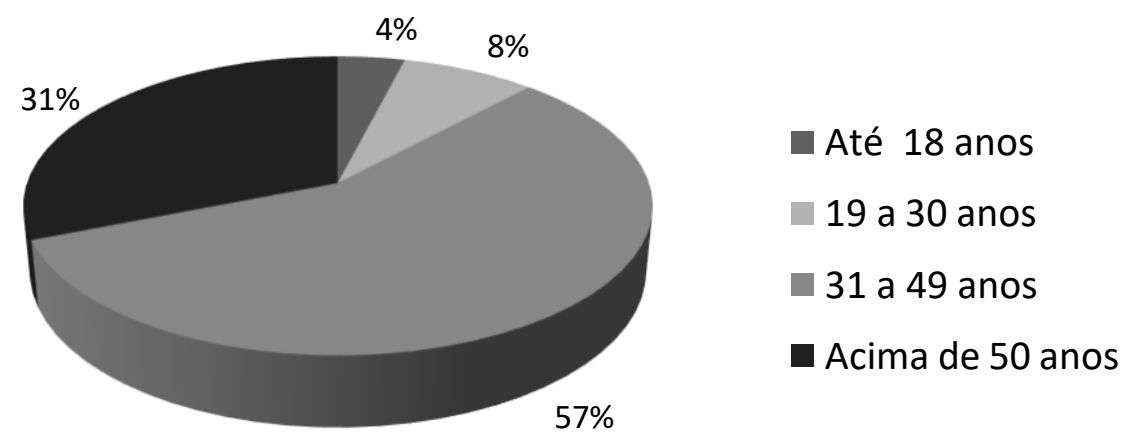

Fonte: Dados da pesquisa (2018).

Observa-se que mais da metade (57\%) tem de 31 a 49 anos de idade, $31 \%$ acima de 50 anos, $8 \%$ de 19 a 30 anos e $4 \%$ até 18 anos.

O gráfico 2 expõe a cor declarada da entrevistada

\section{Gráfico 2 - Cor}

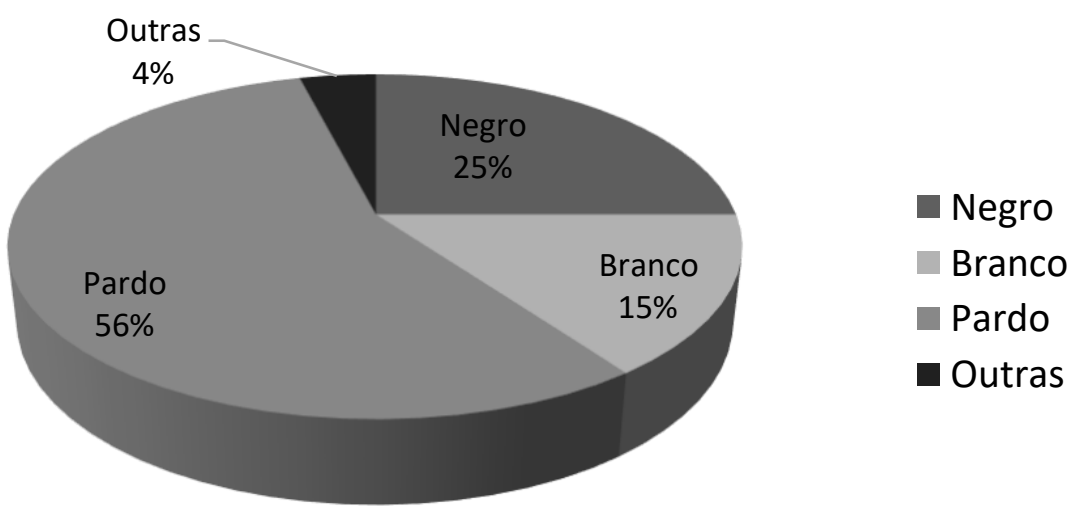

Fonte: Dados da pesquisa (2018).

Com relação à cor declarada pelas entrevistadas da amostra, prevalecem as pessoas autodeclaradas pardas, totalizando $56 \%$ das entrevistadas, seguido pelas autodeclaradas negras. Evidencia-se que os resultados da pesquisa mostram a miscigenação e os mesmos não vão de encontro com o que Damasceno; Chagas (2013) apresentam. 


\section{pontěditora}

A situação da maioria das entrevistadas se declararem pardas ou negras tem relação ao fato histórico do surgimento do trabalhador doméstico no Brasil ter se dado a partir dos escravos africanos, trazidos para a "casa grande" para desempenhar atividades do lar. Em sua maioria, esse tipo de atividade era realizado por homens e mulheres negras e até mesmo crianças (DAMASCENO; CHAGAS, 2013).

O gráfico 3 aponta o nível de escolaridade declarada pelas entrevistadas

\section{Gráfico 3 - Nível de escolaridade}

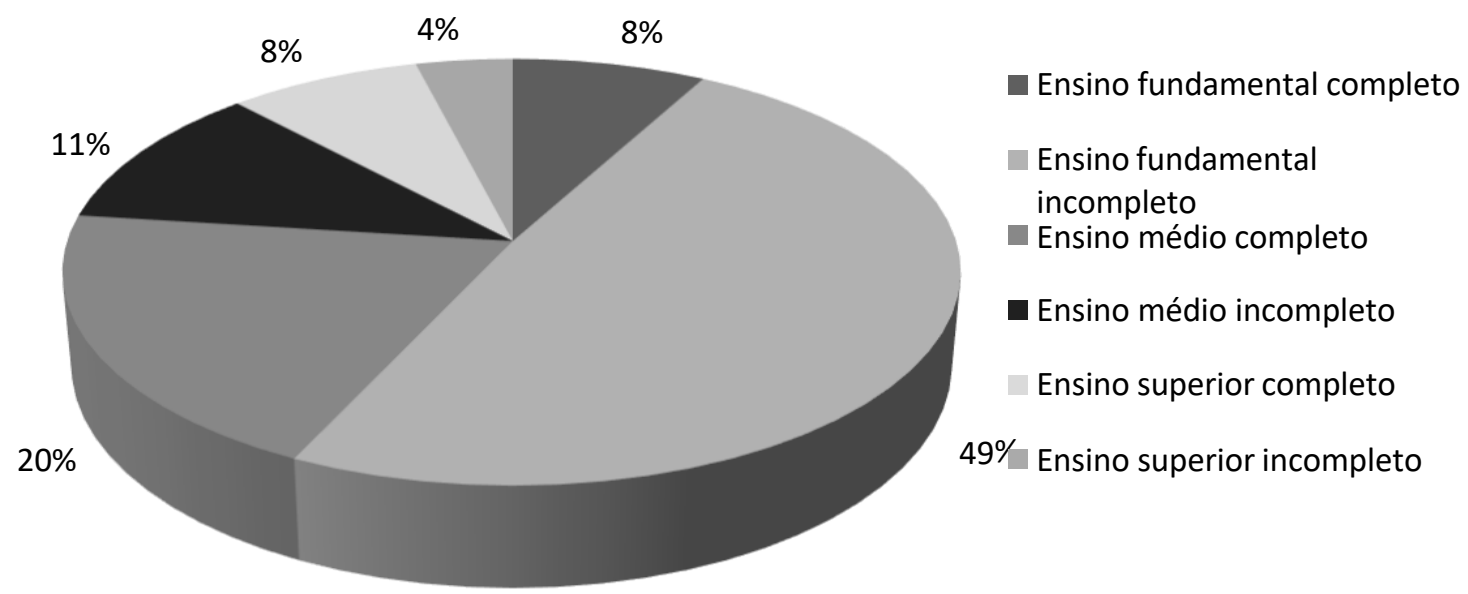

Fonte: Dados da pesquisa (2018).

Nota-se na análise do gráfico 3 que mais da metade das entrevistadas (57\%) possuem apenas o ensino fundamental, e desses $49 \%$ o fundamental incompleto. Nota-se que essa atividade pode ser desempenhada por alguém com pouca formação escolar. Destaca-se que $8 \%$ das entrevistadas possuem ensino superior completo, mas não conseguiram se estabilizar na área formada e procuraram no trabalho doméstico sua renda.

O Gráfico 4 apresenta o tempo de exercício profissional das entrevistadas.

\section{Gráfico 4 - Tempo de exercício}

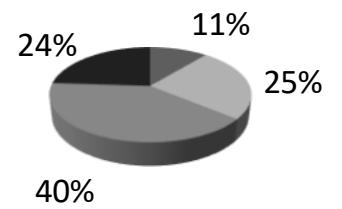

$$
\begin{aligned}
& \text { Menos } \\
& \text { de } 5 \ldots
\end{aligned}
$$

Fonte: Dados da pesquisa (2018). 
Os resultados do Gráfico 4 demostram a predominância de mulheres que trabalham como empregadas domésticas entre 10 a 25 anos com 40\%, seguido das que trabalham de 5 a 10 anos com $25 \%$ e as que trabalham há mais de 25 anos com $24 \%$. Percebe-se que muitas dessas profissionais já são idosas, mas devido à baixa renda, optam por continuar trabalhando.

O Gráfico 5 aponta a formalização do contrato de trabalho profissional por meio do registro em carteira

\section{Gráfico 5 - Formalização de contrato por meio de registro em carteira}

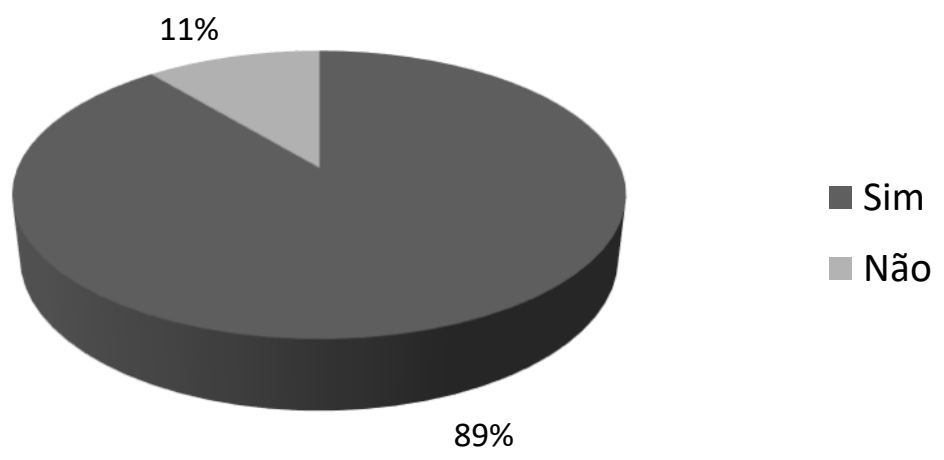

Fonte: Dados da pesquisa (2018).

Nota-se no gráfico 5 que que a maioria das entrevistadas (89\%) trabalham com carteira registrada como empregada doméstica e apenas $11 \%$ declaram não possuir formalização do contrato de trabalho por meio do registro em carteira profissional. Evidencia-se que o grupo pesquisado apresenta características divergentes daquele pesquisado pelo IBGE que afirma que em 2016 haviam no Brasil 6.152 milhões de trabalhadores domésticos e que apenas $32 \%$ dos trabalhadores possuíam carteira de trabalho assinada.

A tabela 2 apresenta a função desempenhada no exercício profissional do grupo pesquisado.

Tabela 2 - Função desempenhada

\begin{tabular}{cc}
\hline Respostas & Total de entrevistados \\
\hline Babá & 9 \\
\hline Cozinheira(o) & 8 \\
\hline Acompanhante de idosos & 12 \\
\hline Serviços gerais & 71 \\
\hline TOTAL & 100 \\
\hline Fonte: Dados da pesquisa (2018).
\end{tabular}

Fonte: Dados da pesquisa (2018). 


\section{pontěditora}

Os resultados apresentados na Tabela 2 aponta que 71\% das empregadas declararam desempenhar a função de serviços gerais, 12 atuam como acompanhante de idosos, 9 são babás e 8 são cozinheiras.

O Gráfico 6 expõe o grau de satisfação que essas profissionais sentem com o próprio trabalho.

\section{Gráfico 6 - Grau de satisfação com o trabalho}

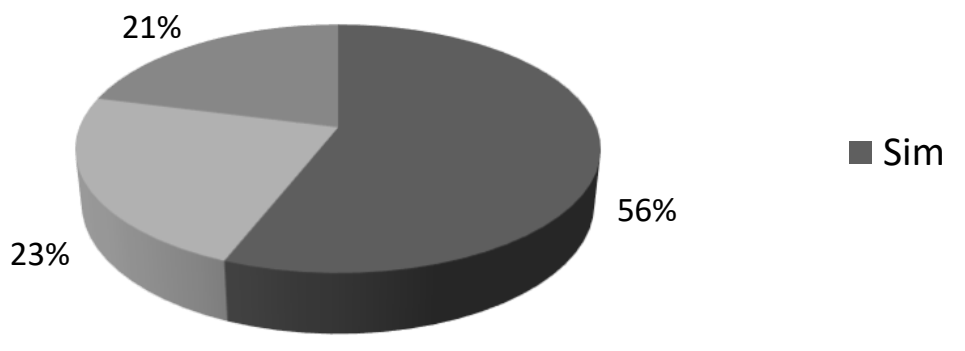

Fonte: Dados da pesquisa (2018).

Os resultados sugerem que mais da metade $(56 \%)$ das entrevistadas disseram estar satisfeitas com o próprio trabalho. Seguindo, $23 \%$ declararam não estarem satisfeitas e $21 \%$ declararam estarem parcialmente satisfeitas.

O Gráfico 7 aponta quantas das profissionais pesquisada gostariam de exercer outra atividade profissional

\section{Gráfico 7 - Gostariam de exercer outra atividade profissional}

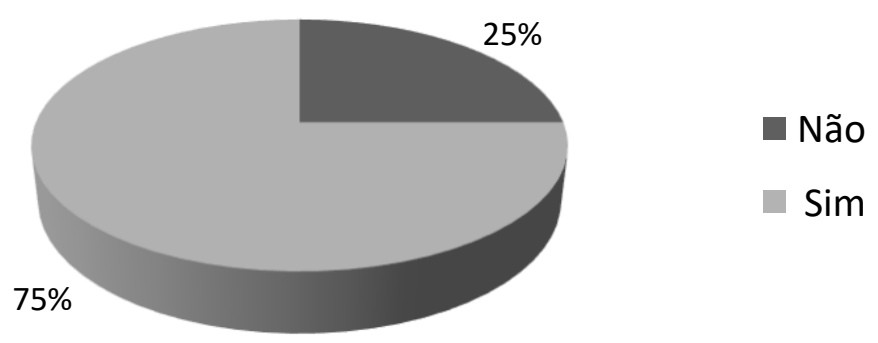

Fonte: Dados da pesquisa (2018).

Apesar de mais da metade das profissionais estarem satisfeitas com a profissão, pode-se

$e^{3}$ - Revista de Economia, Empresas e Empreendedores na CPLP | Volume 4 | Número 2 


\section{pontěditora}

observar na análise do Gráfico 7 que 75\% das entrevistadas declararam que gostariam de exercer outra atividade profissional. Dentre essas atividades foram citadas: professora, jornalista, advogada, cozinheira, escritora, segurança, policial, juíza entre outras.

A tabela 3 apontam os fatores que as levaram a exercer a atividade de empregada doméstica.

\section{Tabela 3 - Fatores que levou a profissional a exercer esse tipo de atividade}

\begin{tabular}{cc}
\hline Respostas & Total de entrevistados \\
\hline Gostar da atividade & 28 \\
\hline Me sinto importante com o trabalho que exerço & 5 \\
\hline Falta de oportunidade & 67 \\
\hline TOTAL & 100 \\
\hline Fonte: Dados da pesquisa (2018).
\end{tabular}

Quanto ao que levou a entrevistada a exercer a atividade, 67\% declararam falta de oportunidade, principalmente relacionada a escolaridade. $28 \%$ declararam gostar de atividade e 5\% declararam se sentirem importantes com o trabalho que exercem.

No Gráfico 8 foi apresentado quantas entrevistadas declaram fazer intervalo para repouso ou alimentação.

\section{Gráfico 8 - Faz intervalo para repouso ou alimentação}

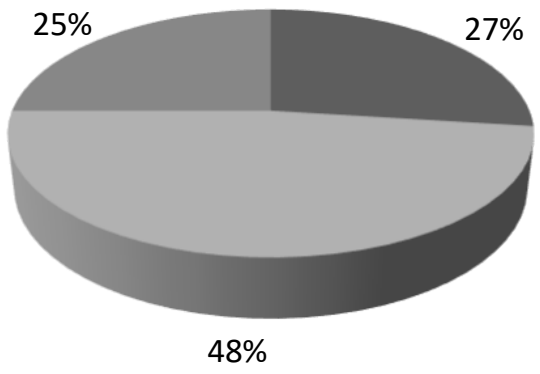

- Sim

Não

As vezes

Fonte: Dados da pesquisa (2018).

Percebe-se que $48 \%$ das entrevistadas declararam não fazer intervalo para repouso ou alimentação, 27\% declararam usufruir desse período de intervalo e 25\% declaram que as vezes dispõem desse intervalo. Algumas entrevistadas declararam que não fazem pausas 


\section{pontěditora}

para repouso e alimentação para terminarem antes do horário de expediente.

O Gráfico 9 aponta o número de entrevistadas que declaram receber férias normalmente Gráfico 9 - Recebe férias normalmente

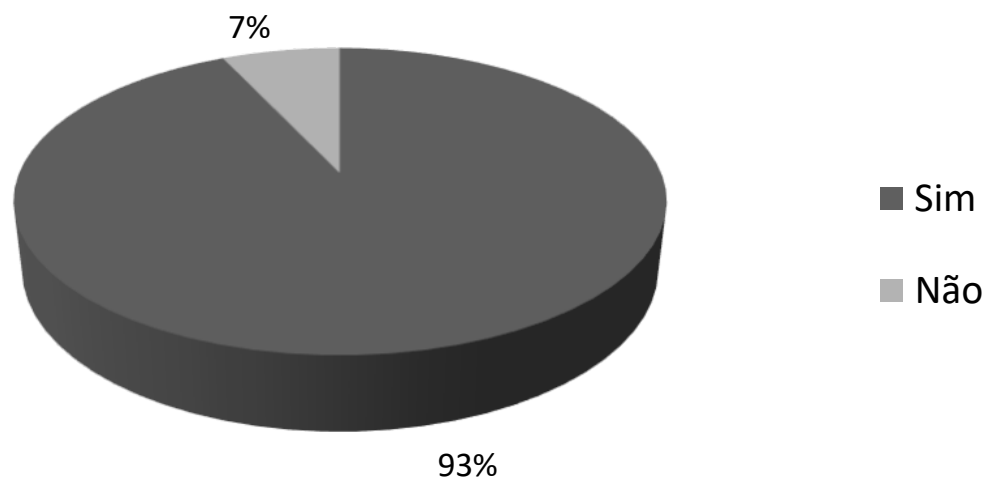

Fonte: Dados da pesquisa (2018).

Nota-se que $93 \%$ das entrevistadas afirmaram receber e gozar férias normalmente. Fato esse que se equipara e tem relação com o grande número de empregadas que trabalham com carteira assinada apresentados no gráfico 5 .

O Gráfico 10 apresenta o número de entrevistadas que declaram receber $13^{\circ}$ salário.

\section{Gráfico 10 - Recebe $13^{\circ}$ salário}

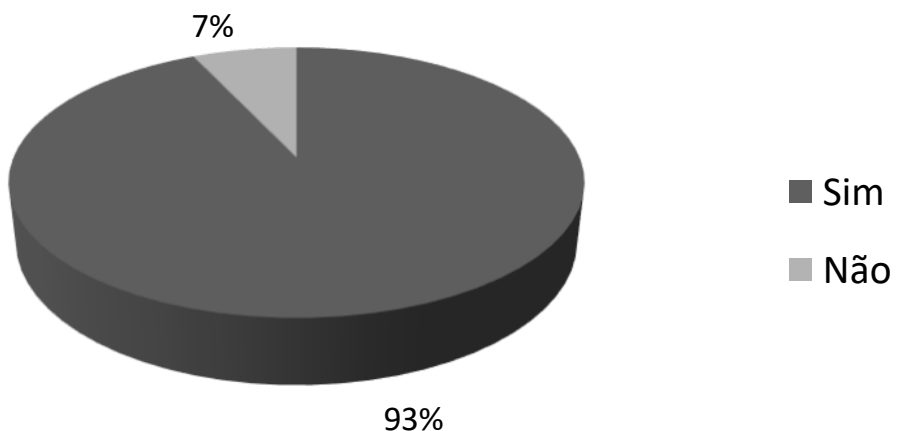

Fonte: Dados da pesquisa (2018).

De acordo com os resultados obtidos e apontados no Gráfico 10, 93\% das entrevistadas disseram receber $13^{\circ}$ salário e apenas $7 \%$ afirmaram que não recebem. As entrevistadas 


\section{pontěditora}

que não recebem são diaristas, ou seja, não possuem carteira de trabalho registrada e por isso esse direito não é garantido a elas. Durante a pesquisa pôde ser observado que as diaristas são as que enfrentam as condições mais precárias de trabalho, hoje trabalhando cerca de 2 vezes na semana. As mesmas explicaram que os empregadores deixam o serviço acumular até o dia das diaristas voltarem para fazer o serviço novamente. Fato que mostra que as diaristas enfrentam situações menos favoráveis de trabalho.

O Gráfico 11 aponta o número de entrevistados que tem as horas extras devidamente pagas quando há necessidade de estender o horário de trabalho ou trabalhar em dias de folga.

\section{Gráfico 11 - horas extras devidamente pagas}

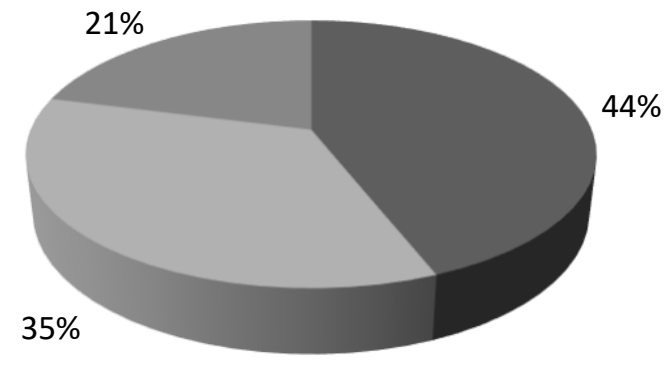

- Sim

Fonte: Dados da pesquisa (2018).

Observa-se que $44 \%$ das entrevistadas afirmam que recebem devidamente as horas extras feitas, seguido de $35 \%$ que afirmaram não receber as horas extraordinárias e $21 \%$ disseram que as vezes são pagas. Esses dados atestam que que nem sempre os direitos são integralmente garantidos.

O Gráfico 12 aponta o conhecimento das entrevistadas em relação aos direitos trabalhistas garantidos pela legislação

Gráfico 12 - Possui conhecimento em relação aos direitos trabalhistas garantidos pela legislação

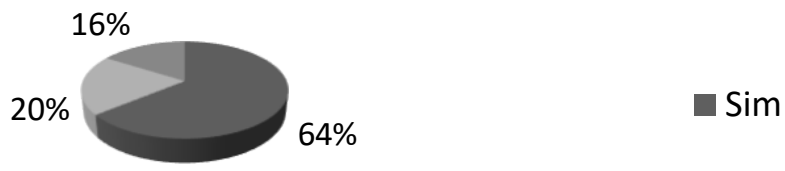

Fonte: Dados da pesquisa (2018). 
Os resultados analisados e apresentados no Gráfico 12 apontam que mais da metade das entrevistadas (64\%) declararam ter conhecimento a respeito dos seus direitos trabalhistas, $20 \%$ declaram não terem conhecimento e $16 \%$ declaram conhecerem parcialmente seus direitos garantidos em lei.

A tabela 4 aponta como os entrevistados tomaram conhecimento dos seus direitos.

Tabela 4 - Fonte de conhecimentos dos seus direitos

\begin{tabular}{cc}
\hline Respostas & Total de entrevistados \\
\hline Jornal & 15 \\
\hline TV & 32 \\
\hline Conversa com patrões & 10 \\
\hline Conversa com colegas de profissão & 4 \\
\hline Conversa com familiares e amigos & 3 \\
\hline TOTAL & 64 \\
\hline
\end{tabular}

Fonte: Dados da pesquisa (2018).

A partir da leitura da tabela 4 percebe-se que $32 \%$ tomaram conhecimento dos seus direitos por meio da TV, 15\% por meio de jornal, $10 \%$ por meio de conversas com patrões, $4 \%$ com colegas de profissão e $3 \%$ por conversas com familiares e amigos.

O Gráfico 13 aponta a percepção das entrevistadas sobre mudanças em relação as oportunidades de trabalho.

\section{Gráfico 13 - Percepção sobre mudanças em relação as oportunidades de trabalho}

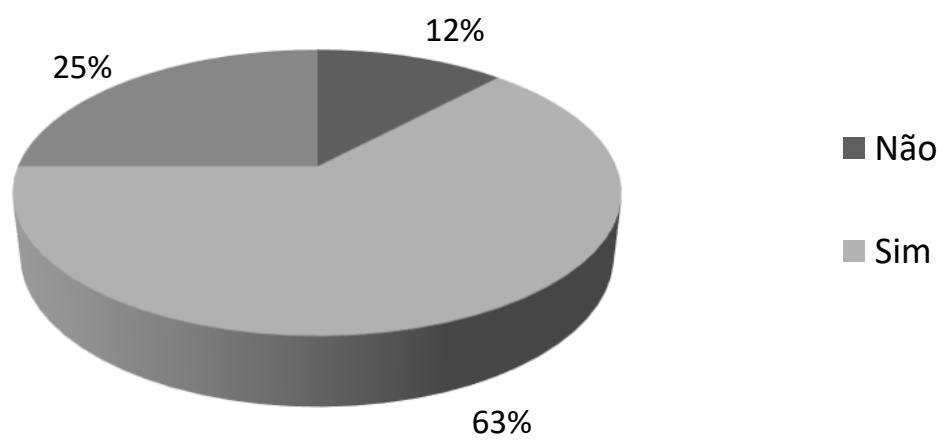

Fonte: Dados da pesquisa (2018).

Observa-se que $63 \%$ das entrevistadas declararam ter percebido mudanças quanto as oportunidades de trabalho, $12 \%$ declaram não ter percebido e $25 \%$ não sabem ou não quiseram opinar. 


\section{pontěditora}

A tabela 5 sugere os tipos de mudança percebidas pelas entrevistadas na atividade profissional após a regulamentação da lei.

Tabela 5 - Mudança percebida pelas entrevistadas

\begin{tabular}{cc}
\hline Respostas & Total de entrevistados \\
\hline Aumento das oportunidades de trabalho & 11 \\
\hline Redução das oportunidades de trabalho & 35 \\
\hline Aumento dos benefícios decorrentes do trabalho & 14 \\
\hline Aumento da renda mensal & 3 \\
\hline TOTAL & 63
\end{tabular}

Fonte: Dados da pesquisa (2018).

Como resultado apresentado na Tabela 5, tem-se que 35\% dos entrevistados declararam que perceberam uma redução das oportunidades de trabalho, seguido das que declararam ter percebido aumento das oportunidades de trabalho com $11 \%$. Para $14 \%$ ocorrei aumento dos benefícios decorrentes da relação trabalhista e apenas 3\% da amostra disseram ter percebido aumento da renda mensal.

O Gráfico 14 aponta a média salarial declarada pelas entrevistadas.

\section{Gráfico 14 - Média salarial}

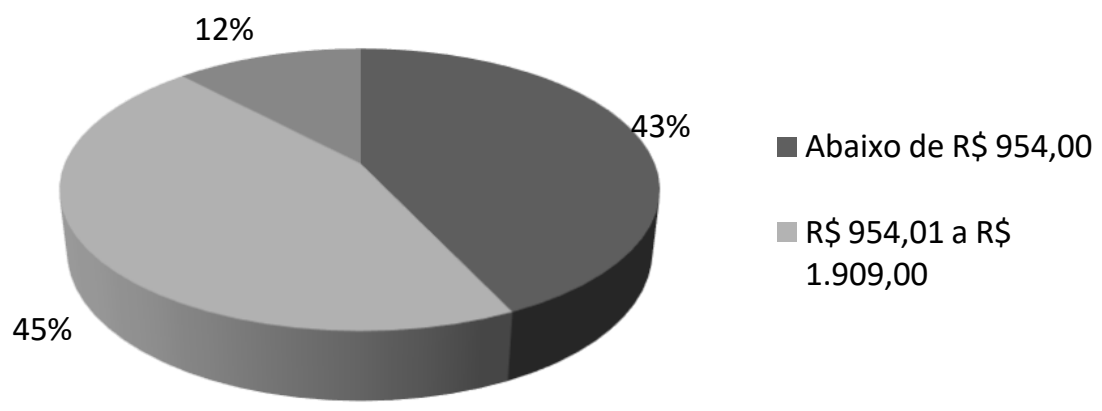

Fonte: Dados da pesquisa (2018).

Os resultados expressos no Gráfico 14 demonstram que 43\% recebem até um salário mínimo, $45 \%$ das entrevistadas recebem mais de 1 até 2 salários mínimos e 12\% recebem mais de 2 salários mínimos. Esse fato pode estar associado a questão da baixa escolaridade de grande parte das entrevistadas. 


\section{pontěditora}

\section{5 - Considerações finais}

O objetivo desse trabalho constituiu em analisar o conhecimento do trabalhador doméstico a respeito dos seus direitos e analisar se seus direitos são garantidos, assim como levantar os perfis demográficos dos profissionais entrevistados.

Os resultados da pesquisa revelam no Gráfico 5 que quase $90 \%$ das entrevistadas possuem carteira de trabalho assinada. Fato que pode ser um dos motivos de a maior parte das profissionais estarem cientes dos seus direitos trabalhistas garantidos pela legislação. Situação a qual foi apresentada no Gráfico 13, que demostra que 64\% das entrevistadas tem conhecimento.

Vale ressaltar que alguns casos foram observados que os direitos não são garantidos, como demostra nos gráficos 8, 9, 10 e 11. Direitos como: fazer intervalo para repouso e alimentação e horas extras devidamente pagas. Essa situação pode acontecer pelo fato do trabalho doméstico ter a característica específica de ser realizado dentro de casa e não ter modos de registrar horário de chegada e saída da funcionária, assim como ser dificultada a fiscalização.

A pesquisa ainda demonstra que 63\% das empregadas domésticas perceberam algum tipo de mudança com relação as oportunidades de trabalho após a lei complementar, que regulamentou os direitos do profissional doméstico em 2015. Dos 63\% de pessoas que declaram ter percebido mudanças, mais da metade declaram que perceberam redução das oportunidades de trabalho, seguindo de 11 que declaram ter percebido aumentado o número das oportunidades de trabalho. Muitas empregadas atestam que devido as novas leis trabalhistas, empregadores não conseguiram cumprir com os deverem e acabaram tendo que despedir a empregada. Assim, várias pessoas deixaram de ser empregadas domésticas e passaram a ser diaristas.

Os resultados da pesquisa também demonstram que, como perfil demográfico, mais da metade das empregadas entrevistadas (57\%) tem entre 31 e 49 anos de idade e $31 \%$ tem mais de 59 anos, sendo que a maioria delas relatam terem vindo do interior do estado em busca de trabalho e melhores condições de vida. A partir da análise do Gráfico 1 que mostra que apenas 4\% das entrevistadas tinham até 18 anos e $8 \%$ tinham de 19 a 30 


\section{pontěditora}

anos, é possível observar a tendência das jovens a não se tornarem empregadas domésticas, em razão das maiores oportunidades de estudo e trabalho. Ainda em relação ao perfil demográfico, mais da metade das entrevistadas declararam ser da cor parda e $49 \%$ possuem ensino fundamental incompleto.

A partir da metodologia aplicada na realização desse trabalho, é possível entender que a nova lei trouxe melhorias na garantia dos direitos dos trabalhadores domésticos. No entanto, limitou o acesso ao mercado de trabalho. Muitas empregadas atestaram durante as entrevistas que devido às novas leis trabalhistas, empregadores não conseguem cumprir com os deveres e acabam tendo que despedir a empregada e contratar diaristas. Estas não têm qualquer garantia de direitos trabalhistas. Esse fato nos leva a concluir que há a possibilidade de o desemprego aumentar, visto a demissão das empregadas doméstica. 


\section{pontěditora}

\section{Referências bibliográficas}

AGÊNCIA DE NOTÍCIAS IBGE. Trabalho doméstico reduz desocupação, mas reforça informalidade. nov. $2017 . \quad$ Disponível em: $<$ https://agenciadenoticias.ibge.gov.br/agencia-noticias/2012-agencia-denoticias/noticias/18435-trabalho-domestico-reduz-desocupacao-mas-reforcainformalidade.html>. Acesso em: 15 abr. 2018.

ARAÚJO, M.M. Trabalho doméstico no Brasil: a luta pelo reconhecimento social frente aos novos direitos. 2015. 65 f. Trabalho de Conclusão de Curso (Graduação em Ciências Sociais com Habilitação em Sociologia) - Departamento de Sociologia, Instituto de Ciências Socias, Universidade de Brasília, Brasília, 2015. Disponível em: $<$ http://bdm.unb.br/bitstream/10483/11482/1/2015_MarinaMacedoAraujo.pdf $>$. Acesso em: 15 abr. 2018.

BARBOSA, M.L.S. Emenda Constitucional 72 de 2013 e seus efeitos na sociedade. 2015. 37 f. Monografia (Graduação em Direito) - Faculdade Cearense, Fortaleza, 2015. Disponível em: $<$ https://www.faculdadescearenses.edu.br/biblioteca/TCC/DIR/EMENDA\%20CONSTI TUCIONAL\%2072\%20DE\%202013\%20E\%20SEUS\%20EFEITOS\%20NA\%20SOCI EDADE.pdf $>$. Acesso em: 15 abr. 2018.

BARROS, V.A. Qualificação profissional do trabalhador doméstico no Brasil: análise na perspectiva do trabalho decente. 2013. 33p. Tese (Doutorado em Direito do Trabalho) - Faculdade de Direito, Universidade de São Paulo, São Paulo, 2013. Disponível em: $\quad<$ http://www.teses.usp.br/teses/disponiveis/2/2138/tde-18112016094221/>. Acesso em: 15 abr. 2018.

BRA SIL. Ministério do Trabalho e Emprego. Trabalho doméstico: direitos e deveres: orientações. 5. ed. Brasília: Secretaria de Inspeção do Trabalho (SIT) - MTE, SIT, 2013.

BRASIL. Ministério do Trabalho e Previdência Social. Trabalhadores domésticos: direitos e deveres. 6. ed. Brasília: Secretaria de Inspeção do Trabalho (SIT) - MTE, SIT, 


\section{pontěditora}

2015.

COZBY, Paul C. Métodos de Pesquisa em Ciências do Comportamento. 3. ed. São Paulo: Atlas, 2006.

CUNHA, O. M. G.; GOMES, F. S. (Orgs.). Quase-cidadão: histórias e antropologia da pós-emancipação no Brasil. Rio de Janeiro: FGV, 2007.

DAMASCENO, L.D.; CHAGAS, S.O. Evolução do direito trabalhista do empregado doméstico de 1916 a 2013 - PEC das domésticas. Cadernos de Graduação - Ciências Humanas e Sociais, Aracaju, v. 1, n.17, p.63-76, out 2013. Disponível em: $<$ https://periodicos.set.edu.br/index.php/cadernohumanas/article/download/888/500>. Acesso em: 16 mar. 2018

FARACO, M. Os Direitos das empregadas domésticas e a diferenciação entre empregada doméstica e diarista. JusBrasil, 15 out. 2014. Disponível em: $<$ http://marcelafaraco.jusbrasil.com.br/publicacoes>. Acesso em: 21 mar. 2018.

FIGUEIREDO, N. Método e metodologia na pesquisa científica. 2. ed. São Paulo. Yendis, 2007.

FORTIN, M.F. O processo de investigação: da concepção à realização. 3. ed Loures: Lusociência, Ed.Técnicas e Científicas Ltda, 2003.

GIL, A. C. Como elaborar projetos de pesquisa. 4. ed. São Paulo. Atlas, 2008.

MACIEL, J. Novos direitos trabalhistas dos empregados domésticos após a regulamentação da emenda Constitucional 72/2013 pela Lei Complementar n. 150/2015. 2016. 105 f. Trabalho de Conclusão de Curso (Graduação em Direito) - Departamento de Direito, Centro de Ciências Jurídicas, Universidade Federal de Santa Catarina, Florianópolis, $2016.2105 \mathrm{p}$ Disponível em: $<$ https://repositorio.ufsc.br/xmlui/handle/123456789/166585>. Acesso em: 21 mar. 2018. 


\section{pontěditora}

MARTELETO, B.S. Os direitos trabalhistas dos empregados domésticos no Brasil com ênfase na diferenciação jurídica e nos conflitos sociais. 2011. 63 f. Trabalho de Conclusão de Curso (Graduação em Direito) - Faculdade de Ciências Jurídicas e Sociais de Barbacena, Universidade Presidente Antônio Carlos. Barbacena, 2011. Disponível em: <http://www.unipac.br/site/bb/tcc/tcc-789ecbfe2e58f1157e13e37a89b166b1.pdf $>$. Acesso em: 21 mar. 2018.

MATTAR, F. N. Pesquisa de marketing: edição compacta. 4. ed. São Paulo: Atlas, 2008.

MARTINS, J. E. L. A evolução histórica dos direitos dos empregados domésticos e a PEC 72/2013. 2013. 55 f. Trabalho de Conclusão de Curso (Graduação em Direito) Curso de Direito, Faculdade de Ciências Jurídicas, Universidade Tuiuti do Paraná, Paraná, 2013. Disponível em: <http://tcconline.utp.br/wp-content/uploads/2014/02/AEVOLUCAO-HISTORICA-DOS-DIREITOS-DOS-EMPREGADOS-DOMESTICOSE-A-EC-72-2013.pdf>. Acesso em: 21 mar. 2018.

MARTINS, P. P. Manual do trabalho doméstico. 7. ed. São Paulo: Atlas, 2004.

MIKOS, N.R.C. Trabalho doméstico no Brasil: os reflexos trabalhistas e previdenciários da nova regulamentação 2015. 83 f. Monografia (Graduação em Direito) - Curso de Graduação em Direito, Setor de Ciências Jurídicas, Universidade Federal do Paraná, Curitiba, 2015. Disponível em: $<$ https://acervodigital.ufpr.br/bitstream/handle/1884/42285/58.pdf?sequence=1\&isAllo wed $=\mathrm{y}>$. Acesso em: 21 mar. 2018.

MUNHOZ, E.A.P. et al. A nova Lei das Domésticas: da equiparação à dedução IRPF. Âmbito jurídico, Rio Grande, n. 159, abr. 2017. Disponível em: $<$ http://ambitojuridico.com.br/site/?n_link=revista_artigos_leitura\&artigo_id=18827>. Acesso em: 23 mar. 2018.

PED - PESQUISA DE EMPREGO E DESEMPREGO. Pesquisa de emprego e $\mathrm{e}^{3}$ - Revista de Economia, Empresas e Empreendedores na CPLP | Volume 4 | Número 2 
desemprego na região metropolitana de Belo Horizonte 2014.

Disponível em: <http://www.fjp.mg.gov.br/index.php/produtos-e-servicos1/2767pesquisa-de-emprego-e-desemprego-na-regiao-metropolitana-de-belo-horizonte-pedrmbh-tipo>. Acesso em: 20 abr. 2018.

SILVA, D.F. Trabalho doméstico: as implicações da nova lei da empregada doméstica sobre o sentido, significado e qualidade de vida no trabalho. 2017. 194 f. Dissertação (Programa de Pós-Graduação em Economia Doméstica) - Universidade Federal de Viçosa, Viçosa, 2017. Disponível em: $<$ http://www.locus.ufv.br/bitstream/handle/123456789/11832/texto\%20completo.pdf?se quence $=1>$. Acesso em: 21 abr. 2018.

SILVA, J.V.M. Trabalhadoras domésticas e luta por reconhecimento: novos e velhos impasses para além da igualação de direitos. In: Encontro da ASSOCIAÇÃO NACIONAL DE DIREITOS HUMANOS, PESQUISA E PÓS-GRADUAÇÃO Direitos Humanos, Sustentabilidade, Circulação Global e Povos Indígenas, 9.,2016, Vitória. Anais... Vitória: ANDHEP 2016. p.1-18. Disponível em: $<$ http://www.andhep2016.sinteseeventos.com.br/arquivo/downloadpublic?q=YToyOntz OjY6InBhcmFtcyI7czozNDoiYToxOntzOjEwOiJJRF9BUIFVSVZPIjtzOjM6IjQxOSI7 fSI7czoxOiJoIjtzOjMyOiJkNzVmYmRhMmE5YmU5NDA5OTI5MDlmMmFiN2VhZ DRiZiI7fQ\%3D\%3D>. Acesso em: 22 abr. 2018.

OIT BRASÍLIA. Organização Internacional do Trabalho - Brasília. Trabalho doméstico. 2018. Disponível em: <http://www.ilo.org/brasilia/temas/trabalho-domestico/lang-pt/index.htm>. Acesso em: 21 abr. 2018.

OIT. Domestic workers across the world: Global and regional statistics and the extent of legal protection. Geneva: International Labour Office 2013. Disponível em:

$<$ http://www.ilo.org/wcmsp5/groups/public/@dgreports/@dcomm/@publ/documents/pu blication/wcms_173363.pdf\&gt>. Acesso em: 10 abr. 2018.

POLIT, D. F.; BECK, C. T.; HUNGLER, B. P. Fundamentos de pesquisa em $e^{3}$ - Revista de Economia, Empresas e Empreendedores na CPLP | Volume 4 | Número 2 


\section{pontěditora}

enfermagem: métodos, avaliação e utilização. 5. ed. Porto Alegre: Artmed, 2004.

VERGARA, S. C. Projetos e relatórios de pesquisa em administração. 8. ed. São Paulo:

Atlas, 2007.

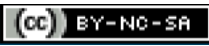

Otrabalho $\mathrm{e}^{3}$ - Revista de Economia, Empresase Empreendedores na CPLP estálicenciadocomuma Licença CreativeCommons - Atribuição-NãoComercial-Compartilha Igual4.0 Internacional. 